\title{
This is not a taste test
}

\author{
Asvin M. Ganapathi, MD, and Nahush A. Mokadam, MD
}

As with many things in life, people often choose between 2 well-known commodities. Nike versus Reebok or McDonald's versus Burger King are some common debates; one of the most famous debates centered over which soda people preferred: Coca-Cola or Pepsi? In the 1980s, Pepsi Cola set up “The Pepsi Challenge." People were asked to blindly taste Pepsi or Coca-Cola and then say which they preferred. As expected, Pepsi was the chosen drink featured in televised commercials. Although this allowed Pepsi to gain market share, it did not ultimately unseat Coca-Cola as the leader. This has been thought related to preconceived notions about the products, biases related to a quick taste test, as well as the marketing of the established brand. ${ }^{1}$

In this issue of The Journal, there is an expert opinion discussion of the use of multi-arterial grafting (MAG) for coronary artery bypass grafting (CABG). Vallely and colleagues $^{2}$ and Kurlansky ${ }^{3}$ present their viewpoints and evidence regarding the use of multiple arterial grafts in CABG. Kurlansky provides an extensive overview of the current literature regarding MAG as well providing a commentary on a recent paper by Chikwe and colleagues that examines New Jersey registry data, which demonstrated a survival benefit for MAG. ${ }^{4}$ He provides a call to arms at the end to help determine which patients will most benefit from $\mathrm{MAG}^{3}$ In contrast, Vallely and colleagues provide a strong opinion about the advantages of more universal MAG as well as anaortic CABG. This piece focuses on perceived obstacles to MAG as well as identifying potential areas in which to help grow the practice of MAG.

As a specialty, CABG remains one of the most common cardiac operations. In many ways, the debate of MAG versus single arterial grafting is like Coca-Cola versus Pepsi: surgeons, cardiologists, and institutions have their biases toward $\mathrm{CABG}$; the mindset can be affected by recent experiences like a taste test, and the trainees often practice how they were taught. Nearly 35 years ago, the publication from Loop and colleagues ${ }^{5}$ established the advantage of the

\footnotetext{
From the Division of Cardiac Surgery, Department of Surgery, The Ohio State University Wexner Medical Center, Columbus, Ohio.

Disclosures: Dr Mokadam reported consultant and investigator for Abbott, Medtronic, Carmat, and SynCardia. Dr Ganapathi reported no conflicts of interest.

The Journal policy requires editors and reviewers to disclose conflicts of interest and to decline handling or reviewing manuscripts for which they may have a conflict of interest. The editors and reviewers of this article have no conflicts of interest.

Received for publication June 8, 2020; revisions received June 8, 2020; accepted for publication June 11, 2020; available ahead of print June 24, 2020.

Address for reprints: Nahush A. Mokadam, MD, Division of Cardiac Surgery, The Ohio State University Wexner Medical Center, N-825 Doan Hall, 410 West 10th Ave, Columbus, OH 43210 (E-mail: Nahush.Mokadam@osumc.edu).

J Thorac Cardiovasc Surg 2021;161:1827

$0022-5223 / \$ 36.00$

Copyright (c) 2020 by The American Association for Thoracic Surgery

https://doi.org/10.1016/j.jtcvs.2020.06.018
}

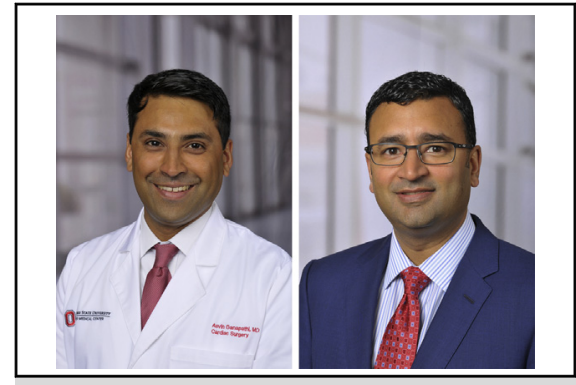

Asvin M. Ganapathi, MD (left), and Nahush A. Mokadam, MD (right)

\section{CENTRAL MESSAGE \\ This choice for surgeons should not be a taste test.}

See Articles on pages 1198 and 1202. left internal mammary and is a mark by which surgeons and institutions are graded, yet similar manuscripts have not had the same impact for the use of bilateral mammary or radial arteries. $^{6,7}$ There is a wealth of evidence out there. We should use it!

\section{References}

1. Yglesias M. Pepsi paradox: Why people prefer Coke even though Pepsi wins in taste tests. Vol 2020. Slate 2013. Available at: https://slate.com/business/2013/08/ pepsi-paradox-why-people-prefer-coke-even-though-pepsi-wins-in-taste-tests. html. Accessed May 20, 2020.

2. Vallely M, Ramponi F, Seco M, Royse A. Multiarterial grafting: Why is it so hard to convince the masses of the benefits? J Thorac Cardiovasc Surg. 2021;161: 1832-6.

3. Kurlansky P. Multiarterial grafting: the answer to that question. J Thorac Cardiovasc Surg. 2021;161:1828-31.

4. Chikwe J, Sun E, Hannan EL, Itagaki S, Lee T, Adams DH, et al. Outcomes of second arterial conduits in patients undergoing multivessel coronary artery bypass graft surgery. J Am Coll Cardiol. 2019;74:2238-48.

5. Loop FD, Lytle BW, Cosgrove DM, Stewart RW, Goormastic M, Williams GW, et al. Influence of the internal-mammary-artery graft on 10-year survival and other cardiac events. N Engl J Med. 1986;314:1-6.

6. Bakaeen FG, Ravichandren K, Blackstone EH, Houghtaling PL, Soltesz EG Johnston DR, et al. Coronary artery target selection and survival after bilateral internal thoracic artery grafting. J Am Coll Cardiol. 2020;75:258-68.

7. Gaudino M, Benedetto U, Fremes S, Biondi-Zoccai G, Sedrakyan A, Puskas JD et al. Radial-artery or saphenous-vein grafts in coronary-artery bypass surgery. N Engl J Med. 2018;378:2069-77. 